(2) Open Access Full Text Article

ORIGINAL RESEARCH

\title{
Impact of Expression and Genetic Variation of microRNA-34b/c on Cognitive Dysfunction in Patients with Major Depressive Disorder
}

This article was published in the following Dove Press journal: Neuropsychiatric Disease and Treatment

\author{
Ning Sun ${ }^{1,2}$ \\ Chunxia Yang' \\ Xiaoting $\mathrm{He}^{1,3}$ \\ Zhifen Liu' \\ Sha Liu' \\ Xinrong $\mathrm{Li}^{1}$ \\ Yanfang Wang' \\ Ruihua Jin ${ }^{2}$ \\ Kerang Zhang (D)' \\ 'Department of Psychiatry, First Hospital \\ of Shanxi Medical University, Taiyuan, \\ People's Republic of China; ${ }^{2}$ Nursing \\ College of Shanxi Medical University, \\ Taiyuan, People's Republic of China; \\ ${ }^{3}$ University-Town Hospital of Chongqing \\ Medical University, Chongqing, People's \\ Republic of China
}

Correspondence: Ruihua Jin; Kerang

Zhang

Email jrh_xy@163.com;

atomsxmu@vip.163.com
Background: Patients suffering from major depressive disorder (MDD) commonly demonstrate lower performance across multiple cognitive domains. Cognitive impairment is an intrinsic characteristic of MDD status and is often influenced by genetic factors. microRNAs (miRNAs or miRs) have been shown to have important implications in the etiology of MDD. Therefore, we aimed to identify and analyze the impact of expression and genetic variation of $\mathrm{miR}-34 \mathrm{~b} / \mathrm{c}$ on cognitive dysfunction in MDD.

Methods: First, we analyzed miR-34c-5p expression in 48 cases of MDD and 54 healthy controls in a Chinese population using qRT-PCR. We assessed the relationship between the level of miR-34c-5p expression and cognitive performance by Repeatable Battery for the Assessment of Neuropsychological Status (RBANS) and the Trail Making Test (TMT). Second, in order to characterize allelic effects of $\mathrm{miR}-34 \mathrm{~b} / \mathrm{c}$ on cognitive performance in MDD patients, we performed genetic association analysis of single-nucleotide polymorphism (SNP) loci of the MIR34B/C genes with cognitive function in a second group consisting of 531 MDD patients and 267 healthy controls.

Results: We found a significant negative correlation between the level of miR-34c-5p expression and both the language and delayed memory index scores in patients with MDD. We also found a significant positive correlation between the level of miR-34c-5p expression and the time required to complete tests A and B of the TMT. The interaction between the rs 2187473 genotype and the disease was significant for both immediate memory and delayed memory. In the patient group, the rs2187473 CC genotype was significantly associated with higher performance on immediate memory $(F=6.683, \mathrm{p}<0.05)$ and delayed memory tasks $(F=4.221, \mathrm{p}<0.05)$.

Conclusion: Our findings suggest that changes in miR-34c expression level have important impacts on cognitive function in patients with MDD. In particular, the polymorphism rs 2187473 is a potential genetic risk factor for cognitive function in MDD, which may be of clinical use.

Keywords: major depressive disorder, MDD, microRNA-34c, single-nucleotide polymorphism, cognitive function

\section{Introduction}

Major depressive disorder (MDD) is a prevalent psychiatric disorder that is among the most debilitating diseases in the world. ${ }^{1,2}$ MDD commonly leads to significant increases to the probability of morbidity and suicide-associated mortality. ${ }^{3,4}$ Psychiatrically, MDD primarily involves mood disturbances and cognitive impairment. ${ }^{5-9}$ Studies have shown that lower performance in many cognitive domains, such as attention, executive 
functioning, memory, and processing speed, is closely correlated to MDD status. ${ }^{10-12}$ In addition, some persistent neurocognitive deficits may impact the ability of individuals with MDD to recover and have been suggested as a predictive factor for poor treatment response and future recurrence. ${ }^{13,14}$ Cognitive deficits were found to be one of the most significant clinical symptoms of MDD, leading to increased disability and mortality as well as a shortened life expectancy. ${ }^{15-18}$ Moreover, cognitive impairment is thought to be an intrinsic characteristic of MDD that may take precedence over depressive symptoms. ${ }^{19-22}$ Despite such extensive studies, the pathological mechanisms of cognitive deficits in MDD remain uncertain.

Genetic factors play an important role in the development of MDD and associated cognitive deficits. microRNAs (miRs), which comprise a class of small non-coding RNAs (19-22 nt in length), have gained increasing attention for their epigenetic role in modulating neuronal physiology and pathology. $^{23,24}$ Emerging evidence has demonstrated that miRNAs play a critical role in MDD pathogenesis in animal models $^{25}$ and in human subjects. ${ }^{26-30}$ Previous studies have also shown that some miRs may serve as biomarkers for MDD and may imply potential in the treatment of MDD. ${ }^{31,32}$

Among the miRs investigated in studies of MDD, the miR-34 family has received considerable attention. The miR-34 family consists of three miRNAs: miR-34a, miR$34 b$, and miR-34c, which are all involved in cell proliferation, differentiation, and apoptosis. ${ }^{33}$ Previous studies have suggested that miR-34b/c may be involved in stress response and exert antidepressant effects. ${ }^{33,34}$ miR-34c$5 \mathrm{p}$ was found to be overexpressed in the hippocampus in mouse models of Alzheimer's disease, and targeting miR$34 c-5 p$ reversed or impeded the growth of learning deficits in the mice suffering from Alzheimer's disease. ${ }^{35}$ Our group found that higher miR-34c-5p expression levels in peripheral blood leukocytes and allelic variations of MIR34B/C genes were closely related to MDD. ${ }^{36,37}$ In addition, downregulation of the miR-34c level has been shown to improve memory impairment in a ketamineinduced mouse model and in a pentylenetetrazol-induced epileptic rat model, suggesting an important role for miR$34 \mathrm{c}$ level in cognitive function. ${ }^{38,39}$

To further expand upon these findings, we investigated the influence of miR-34c expression in peripheral blood leukocytes and of miR-34b/c single-nucleotide polymorphisms on cognitive dysfunction in MDD. We also evaluated the effects of miR-34c expression and polymorphism on decision-making in patients with MDD as versus healthy controls.

\section{Materials and Methods}

\section{Subjects}

This study focused on the relationship between neuropsychological variables, miR-34c expression levels, and hereditary susceptibility. Two groups were employed and analyzed in this study for expression levels and genetic susceptibility, respectively; these groups were further subdivided into patients with MDD and healthy controls.

The first group consisted of 48 patients with MDD who were recruited from the inpatient department of psychiatry at the First Hospital of Shanxi Medical University between March 2014 and December 2015. The recruitment and diagnosis of the subjects have been described in our previous study. ${ }^{36}$ All patients met the following inclusion criteria: 1) 18-60 years old and 2) either presenting with the first episode of depression or currently diagnosed with depression but never received antidepressant treatment. The exclusion criteria for the patients included severe medical diseases or other psychiatric disorders (eg, schizophrenia and bipolar disorder), pregnancy, or a history of substance abuse or drug addiction. The 17-item Hamilton depressive scale (HAM-D) was used to assess the severity of depressive symptoms. The mean HAM-D score was $22.17 \pm 4.32$. We also recruited a group of 54 heathy controls from the community during the same period. Neither the healthy control participants nor their firstdegree relatives had a history of psychiatric illness.

The second group consisted of a larger population (531 patients diagnosed with MDD) who were recruited from the First Hospital of Shanxi Medical University between August 2008 and January 2014. The recruitment and diagnosis of the subjects have been described previously. ${ }^{37}$ All 531 patients were recruited from clinical settings (inpatient, $n=157$; outpatient, $n=374$ ). Of these patients, $78.2 \%$ were experiencing their first major depressive episode $(\mathrm{n}=$ 415), whereas the other $21.8 \%$ were experiencing a relapse $(\mathrm{n}=116)$. The HAM-D was used to assess the severity of depressive symptoms. The mean total HAM-D score of this sample with MDD was $21.82 \pm 6.03$. We recruited a group of 267 heathy controls from the local community during the same period. Neither the healthy participants nor their first-degree relatives had a history of psychiatric illness. 
Consensus diagnoses for MDD were made by at least two independent psychiatrists according to the criteria specified in the "Diagnostic and Statistical Manual of Mental Disorders Fourth Edition (DSM-IV)". All patients were also assessed using the Chinese version of the Modified Structured Clinical Interview for DSM-IV Text Revision: Axis I Disorders - Patient Edition (SCID-I/P, 11/ 2002 revision).

This study was approved by the Ethical Committee for Medicine of First Hospital of Shanxi Medical University in Taiyuan, China., and conducted in accordance with the Declaration of Helsinki. All subjects provided written informed consent.

\section{Cognitive Tasks}

We used two tools to evaluate neuropsychological function: the Repeatable Battery for the Assessment of Neuropsychological Status (RBANS) and the Trail Making Test (TMT). ${ }^{40-42}$ The RBANS is a neuropsychological assessment first introduced by Randolph et $\mathrm{al}^{43}$ It has been widely used in research settings involving normal subjects, patients with nervous system diseases (Alzheimer disease and Parkinson's disease), and in those with psychiatric diseases (depression and schizophrenia). The RBANS includes 12 subtests and the results are summarized using 5 specific index scores: immediate memory, visuospatial/constructional ability, language, attention, and delayed memory. The RBANS takes approximately 30 minutes to administer and yields scaled index scores for five cognitive domains. The RBANS was previously translated into Chinese and has been demonstrated to have high reliability, test-retest stability, inter-rater reliability, content validity, and construct validity. ${ }^{45,46}$ The TMT is a simple and convenient battery to evaluate cognitive function, especially working memory, and consists of two parts. Part A of the TMT is used to evaluate psychomotor speed, while part B is used for assessment of visuo-spatial performance, working memory, and executive functions. ${ }^{44}$ In TMT part A, the subjects are asked to continuously connect 25 encircled numbers with lines. In TMT-B, the subjects are required to connect correlating numbers with different colors. The time required to complete each test was recorded.

All subjects completed the RBANS and TMT at the stage in which we analyzed their miR-34c expression levels. All patients and controls completed the RBANS at the stage in which we explored hereditary susceptibility. To ensure consistency and reliability of the ratings, the two clinical psychologists simultaneously attended a training session in order to standardize their use of RBANS and
TMT prior to the start of the study. The intraclass correlation coefficients between the scores they obtained were $r>$ 0.90 for RBANS and TMT after repeated assessments.

\section{Sample Preparation and RNA Extraction}

Sample preparation and RNA extraction were performed as previously described. ${ }^{36}$ Blood samples were collected from study participants after fasting for 4 hours using tubes coated with the anticoagulant ethylenediaminetetraacetic acid (EDTA). The integrity of total RNA was evaluated using denaturing agarose gel electrophoresis.

\section{Real-Time Quantitative Reverse Transcription PCR}

The expression of miR-34c-5p was analyzed using quantitative reverse transcription PCR (pRT-PCR), as previously described. ${ }^{36}$ Complementary DNA (cDNA) was synthesized using a High Capacity RNA-to-cDNA Kit (Invitrogen, USA) following the instructions of the manufacturer. The primer used for miR-34c-5p was 5'GAGGCAGTGTAGTTAGCTGATTGC-3'. Expression of miRNA was measured using the miScript system (QIAGEN, CA) according to the protocol provided by the company. Small nuclear RNA U6 was used for normalization. The threshold cycle was defined as the fractional cycle number at which the fluorescence passed the fixed threshold. The comparative threshold cycle $\left(2^{-\Delta \Delta \mathrm{CT}}\right)$ method was used for quantification of transcripts.

\section{Single-Nucleotide Polymorphism (SNP) Analysis}

Isolation of genomic DNA from peripheral blood leukocytes was performed according to a previous method. ${ }^{47}$ SNP genotyping was performed using the MassARRAY platform (Agena Bioscience) and matrix-assisted laser desorption/ionization time-of-light mass spectrometry at BGI-Shenzhen. ${ }^{48,49}$ The sequence of primers and probes has been described previously. ${ }^{37}$ The genotype was analyzed using MassARRAYTM Typer software version 3.1.

To identify specific variants, we retrieved two key tag SNPs (rs4938723 and rs28690953) at MIR34C gene from the HapMap database (http://www.hapmap.org). We excluded the rs28690953 from our analysis because of its low minor allele frequency $(\mathrm{MAF}<0.05)$. In addition, we included two additional SNPs (rs2187473 and rs28757623) located upstream or downstream of the regulatory regions of the precursor or primary MIR34B/C gene (Figure 1). ${ }^{37}$ The 
rs2187473 SNP is located $100 \mathrm{bp}$ downstream of pre-miR $-34 b$, and the rs 28757623 SNP is located 619 bp downstream of pre-miR-34c.

\section{Statistical Analysis}

Statistical analyses were performed using SPSS version 17.0 (SPSS, Chicago, IL, USA). One-sample Kolmogorov-Smirnov Tests were used to assess the normality of the distribution of cognitive task scores in both MDD patients and controls. For cognitive scores that did not follow a normal distribution, we first performed a nonparametric test (Kruskal-Wallis Test), and then transformed the data to rank orders and performed a post hoc analysis using ANOVA. P-values $<0.05$ were considered statistically significant. The genotypic and allelic frequencies between the patient group and the control group were compared by the Pearson $\chi 2$ (Chi-square) analysis. We used the Student's $t$-test (for continuous variables, twotailed) and Chi-square test (for categorical variables) to assess differences in the distributions of demographic characteristics between patients with MDD and control subjects following a normality test. Expression level data were discretized as low or high using a threshold of 50 percentile of median expression. Correlation analyses between the neuropsychological variables and miR-34c-5p expression levels in patients with MDD were performed using Pearson's product-moment correlation coefficient.

Two-way analysis of variance (ANOVA) was used to test the overall effects of the miR-34c expression (discretized as low and high) and genotype on cognitive functions. In the two-way ANOVA analysis, miR-34c expression levels or genotypes of all SNPs and the diagnosis (patient vs control) were entered as fixed factors, and the cognitive task scores were considered dependent variables. Demographic factors including age, sex, and years of education were entered as covariates. The associations between cognitive function and miR-34c expression level or the genotypes of SNPs were tested using parametric testing followed by post hoc analyses for cognitive scores with normal distributions.

To narrow down the number of possible combinations, we only analyzed dominant models. Allele frequencies were calculated by how many times the allele appeared in the population divided by the total number of copies of the gene $(p+q=1 ; p, q$ represents one or the other allele). HardyWeinberg equilibrium for the genotypic distribution of each SNP was tested using the chi-square $(\chi 2)$ goodness-of-fit test.

The calculation follows the equation:

$\chi^{2}=(1-\mathrm{Ho} / \mathrm{He}) 2 \times \mathrm{N}$

Ho $=$ frequency of heterozygotes

$\mathrm{He}=2 \mathrm{pq}$ or the expected frequency value of heterozygotes

$\mathrm{N}=$ total sample size

$d f=1$

$\mathrm{p}<0.05$ was considered significant.

Power analysis for the case-control samples was carried out with PS Version 2.1.31. ${ }^{50}$ In the power analysis, the OR value of three SNPs were 1.25-1.28. To detect a main effect for each polymorphism with a relative risk of 1.25 or greater in an additive mode, given the disorder related gene frequency of 0.35 , a test size of $\mathrm{a}=0.05$ and the sample size of MDD

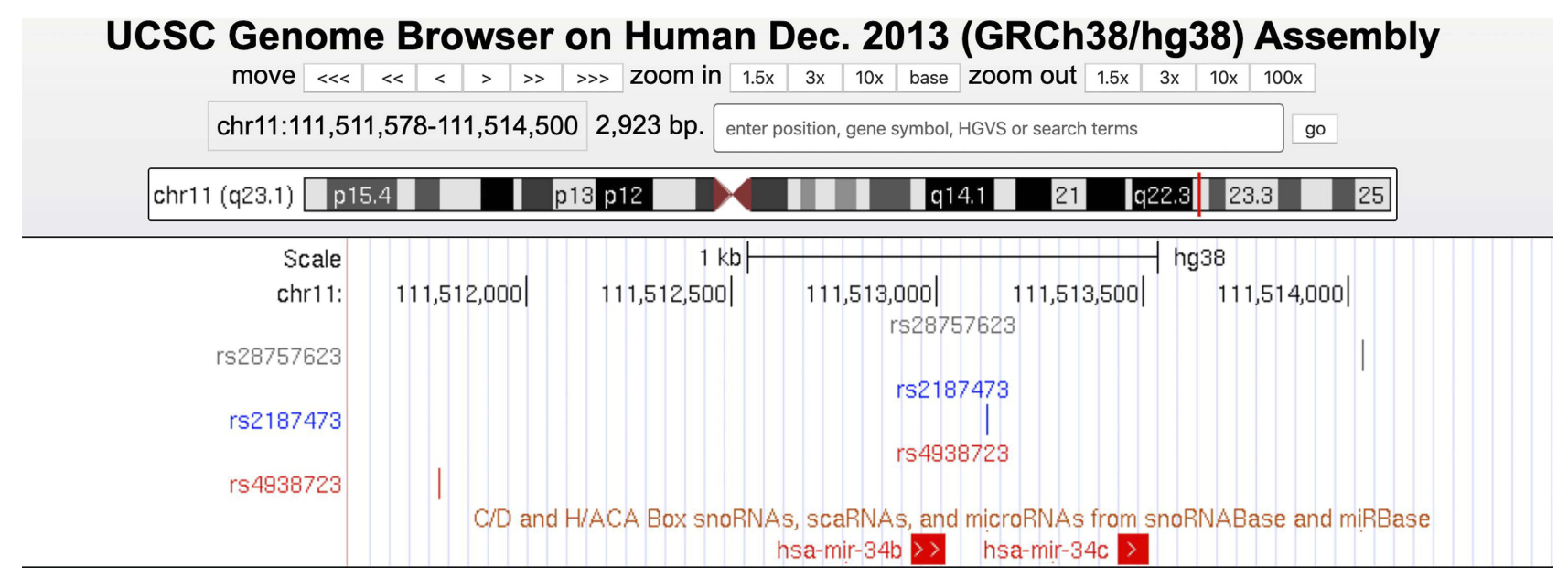

Figure I Physical location of three SNPs located on MIR34B or MIR34C gene. A custom UCSC genome track view showing the physical map of three SNPs (rs28757623, rs2187473, and rs4938723) of the MIR34B or MIR34C gene in the human genome (GRCh38/hg38). 
patients $=450$, control $=230$, the power was estimated to be $64.6 \%$.

\section{Results}

\section{Demographic Data and the MIR34B/C Genotypic Distribution of All SNPs}

For group 1 and group 2, no statistically significant differences were found in terms of age or sex between patients with MDD and controls. However, a statistically significant difference was identified for years of education (Table 1). After controlling for demographic factors, we determined that patients with MDD performed more poorly than the control subjects on all cognitive tasks with the exception of the visuospatial/constructional domain of the RBANS ( $p<$ 0.05 for all). (Tables 2 and 3 ).

The $\chi 2$ goodness-of-fit test showed that the MIR34B/C genotypic distribution of all SNPs was within the HardyWeinberg equilibrium, both in the case group and in the control group, as shown in Table 4. There was no deviation from Hardy-Weinberg equilibrium in any of the SNPs tested ( $p>0.05$ for all). Moreover, genotypic and allelic distributions of all SNPs are shown in Table 4. No significant associations were observed between the genotype and allele frequencies of SNP and MDD ( $p>0.05$ for all).

\section{Correlation Analyses of miR-34c Expression Levels and \\ Neuropsychological Function}

We used Pearson's Correlation to analyze the association between the neuropsychological variables and miR-34c-5p expression levels in patients with MDD. We found a statistically significant negative correlation between the miR-34c-5p expression level and both the language index score $(r=-0.320, \mathrm{p}=0.032)$ and the delayed memory index score in patients with MDD $(r=-0.463, \mathrm{p}=0.001)$. We found significant positive correlations between the miR-34c-5p expression level and the time required to complete both test A $(r=0.375, \mathrm{p}=0.012)$ and test $\mathrm{B}(r=0.477, \mathrm{p}=0.001)$ of the TMT (Figure 2). These data suggested that higher miR-34c-5p expression may be associated with compromised neuropsychological function in MDD patients.

\section{Association Analysis Between miR-34c Expression and Cognitive Functions}

Two-way analysis of variance (ANOVA) was used to test the overall effects of the miR-34c expression level on cognitive functions. After adjusting for age, sex, and years of education, we determined that the relationship between miR-34c-5p expression and diagnosis was significant only for delayed memory $(F=5.464, \mathrm{p}=0.020)$. The main effects of MDD were significant for most items of the RBANS (with the exception of the visuospatial/constructional domain) and all items of the TMT (p<0.05). Patients with MDD performed more poorly than control subjects. To further explore significant interactions, we tested the simple effects separately for patients and controls. While there were no significant associations between expression level and cognitive performance in the controls, MDD patients were more affected by expression level variations; a low level of miR-34c expression in MDD patients was significantly associated with higher performance in the delayed memory domain $(F=11.115, \mathrm{p}=$ 0.001). (Table 2).

\section{Association Analysis Between MIR34B/C Genotype and Cognitive Functions}

Two-way analysis of variance (ANOVA) was used to test the overall effects of the MIR34B/C genotype (rs2187473, rs4938723, and rs2875623) on cognitive functions. For rs2187473, the main effects of diagnosis were significant for all items of the RBANS ( $<<0.05$ ). For rs4938723 and rs2875623, the main effects of diagnosis were significant for most indexes of the RBANS (everything except the visuospatial/constructional domain $)(\mathrm{p}<0.05)$. The patients performed more poorly on cognitive functions than the controls did. After controlling for demographic factors, we determined that the interactions between the

Table I Demographic Characteristics of Participants and Controls

\begin{tabular}{|c|c|c|c|c|c|c|c|c|}
\hline & \multicolumn{4}{|l|}{ Group I } & \multicolumn{4}{|l|}{ Group 2} \\
\hline & Patients $(n=48)$ & Controls $(n=54)$ & $\chi^{2} / \mathbf{t}$ & p-value & Patients $(n=531)$ & Controls $(n=267)$ & $\chi^{2} / \mathbf{t}$ & p-value \\
\hline Sex (male/female) & $14 / 34$ & $21 / 33$ & -1.028 & 0.307 & $229 / 302$ & $120 / 147$ & -0.488 & 0.626 \\
\hline Age (years) & $40.46 \pm 10.47$ & $37.99 \pm 10.26$ & -1.189 & 0.237 & $34.26 \pm 12.06$ & $32.53 \pm 11.26$ & -1.938 & 0.053 \\
\hline Education (years) & $11.96 \pm 3.68$ & $15.19 \pm 3.13$ & 4.768 & $<0.001$ & $11.72 \pm 3.42$ & $13.61 \pm 3.59$ & 7.522 & $<0.001$ \\
\hline
\end{tabular}


Table 2 Association Analysis Between miR-34c Expression and Cognitive Functions

\begin{tabular}{|c|c|c|c|c|c|c|c|}
\hline & Sample & \multicolumn{2}{|c|}{$\begin{array}{l}\text { Cognitive Score (Mean } \pm \text { SD) } \\
\text { Low Expression High Expression }\end{array}$} & $\begin{array}{l}\text { Patients with MDD vs } \\
\text { Controls } F \text { (p-value) }\end{array}$ & $\begin{array}{l}\text { Expression } \\
\text { Effect } \\
F \text { (p-value) }\end{array}$ & $\begin{array}{l}\text { Interaction } \\
F \text { (p-value) }\end{array}$ & $\begin{array}{l}\text { Simple Effect } \\
F \text { (p-value) }\end{array}$ \\
\hline \multicolumn{8}{|l|}{ RBANS: } \\
\hline \multirow[t]{2}{*}{ Immediate memory } & MDD & $62.37 \pm 14.46$ & $55.50 \pm 12.52$ & $12.407(0.001)^{*}$ & $1.561(0.215)$ & $0.287(0.593)$ & \\
\hline & Control & $81.82 \pm 15.62$ & $81.92 \pm 19.77$ & & & & \\
\hline \multirow[t]{2}{*}{ Language } & MDD & $79.12 \pm 14.15$ & $80.89 \pm 15.99$ & $6.147(0.015)^{*}$ & $1.393(0.24 I)$ & $0.026(0.872)$ & \\
\hline & Control & $92.96 \pm 13.53$ & $90.00 \pm 16.60$ & & & & \\
\hline \multirow[t]{2}{*}{ Attention } & MDD & $94.56 \pm 18.16$ & $97.30 \pm 15.98$ & $7.648(0.007)^{*}$ & $0.136(0.714)$ & $0.006(0.939)$ & \\
\hline & Control & $108.93 \pm 16.79$ & $115.58 \pm 15.33$ & & & & \\
\hline \multirow{2}{*}{$\begin{array}{l}\text { Visuospatial/ } \\
\text { constructional }\end{array}$} & MDD & $86.25 \pm 14.84$ & $81.85 \pm 16.81$ & $3.644(0.060)$ & $0.143(0.706)$ & $0.727(0.396)$ & \\
\hline & Control & $94.44 \pm 15.11$ & $92.50 \pm 15.98$ & & & & \\
\hline \multirow[t]{2}{*}{ Delayed memory } & MDD & $84.55 \pm 12.92$ & $70.32 \pm 19.01$ & $10.433(0.002)^{*}$ & $6.880(0.010)^{*}$ & $5.464(0.020) *$ & $11.115(0.001)^{*}$ \\
\hline & Control & $88.75 \pm 10.89$ & $86.04 \pm 15.46$ & & & & $0.040(0.842)$ \\
\hline \multicolumn{8}{|l|}{ Trail making test: } \\
\hline \multirow{2}{*}{$\begin{array}{l}\text { Time required to } \\
\text { complete test } A\end{array}$} & MDD & $77.43 \pm 53.37$ & $104.45 \pm 56.46$ & $24.923(<0.001)^{* *}$ & $1.737(0.191)$ & $2.579(0.112)$ & \\
\hline & Control & $47.33 \pm 18.36$ & $50.29 \pm 20.57$ & & & & \\
\hline \multirow{2}{*}{$\begin{array}{l}\text { Time required to } \\
\text { complete test } B\end{array}$} & MDD & $|37.48 \pm 64.9|$ & $215.18 \pm 118.59$ & $26.156(<0.001)^{* *}$ & $1.435(0.234)$ & $1.988(0.162)$ & \\
\hline & Control & $87.33 \pm 21.85$ & $96.13 \pm 45.74$ & & & & \\
\hline
\end{tabular}

Notes: **p-value $<0.001$. *p-value $<0.05$

rs2187473 genotype and MDD were significant for immediate memory $(F=9.076, \mathrm{p}=0.003)$ and delayed memory $(F=5.014, \mathrm{p}=0.026)$. To further explore the significant interactions reported above, we tested the simple effects separately for patients and controls. In the patients, the rs2187473 CC genotype was significantly associated with higher performance on the immediate memory $(F=6.683, \mathrm{p}=0.010)$ and delayed memory $(F=4.221, \mathrm{p}=0.040)$ items in the dominant model. However, there were no significant associations between genotype and cognitive tasks in the controls (Table 3).

\section{Discussion}

Most studies on depression and neuropsychological functioning use a variety of measures with different psychometric properties. The Repeatable Battery for the Assessment of Neuropsychological Status (RBANS) is a brief neurocognitive test routinely used in clinical settings. ${ }^{43}$ A recent study reported that RBANS is sensitive to the neuropsychological deficits typically found in depression associated with comparable deficits in attention, memory, and visuospatial/ constructional abilities. ${ }^{12}$ In addition, the Trail Making Test (TMT) is a simple and convenient test to evaluate cognitive functioning, especially working memory. ${ }^{44}$ Using these tools, the current study revealed that individuals with Major Depressive Disorder (MDD) had lower cognitive performance in the domains of immediate memory, language, attention, and delayed memory in the RBANS test. Furthermore, patients with MDD required more time to complete tests A and B in the TMT compared with healthy controls. We also found significant negative correlations between miR-34c-5p expression levels and both the language and delayed memory index scores in patients with MDD. We found significant positive correlations between miR-34c-5p expression and the time required to complete both test $\mathrm{A}$ and test B of the TMT. However, we did not see any significant relationship of miR-34b expression to the parameters analyzed in our patient population (data not shown). Moreover, after controlling for demographic factors, we determined that the interaction between expression level and diagnosis was significant for delayed memory. In the MDD patients, a lower expression level was significantly associated with higher 
Table 3 The Association Analysis Between MIR34B/C Genotype and Cognitive Functions

\begin{tabular}{|c|c|c|c|c|c|c|c|}
\hline \multirow[b]{2}{*}{ rs4938723 } & \multirow[t]{2}{*}{ Sample } & \multicolumn{2}{|c|}{ Cognitive Score (Mean \pm SD) } & \multirow{2}{*}{$\begin{array}{l}\text { Cases vs Controls } \\
F \text { (p-value) }\end{array}$} & \multirow{2}{*}{$\begin{array}{l}\text { Genotype Effect } \\
F \text { (p-value) }\end{array}$} & \multirow{2}{*}{$\begin{array}{l}\text { Interaction } \\
F \text { (p-value) }\end{array}$} & \multirow{2}{*}{$\begin{array}{l}\text { Simple Effect } \\
F \text { (p-value) }\end{array}$} \\
\hline & & $\mathrm{CC} / \mathrm{TC}$ & TT & & & & \\
\hline \multirow{2}{*}{$\begin{array}{l}\text { Immediate } \\
\text { memory }\end{array}$} & Case & $75.33 \pm 17.13$ & $72.13 \pm 18.23$ & $31.503(<0.001)^{* *}$ & $0.004(0.952)$ & $2.270(0.132)$ & \\
\hline & Control & $85.83 \pm 16.01$ & $85.77 \pm 15.29$ & & & & \\
\hline \multirow[t]{2}{*}{ Language } & Case & $82.18 \pm 16.78$ & $83.90 \pm 16.55$ & $29.812(<0.001)^{* *}$ & $2.195(0.139)$ & $0.066(0.797)$ & \\
\hline & Control & $91.83 \pm 14.04$ & $92.35 \pm 14.22$ & & & & \\
\hline \multirow[t]{2}{*}{ Attention } & Case & $101.87 \pm 17.60$ & $100.89 \pm 18.44$ & $22.303(<0.001)^{* *}$ & $1.284(0.258)$ & $0.552(0.458)$ & \\
\hline & Control & $111.08 \pm 15.85$ & $109.17 \pm 16.19$ & & & & \\
\hline \multirow{2}{*}{$\begin{array}{l}\text { Visuospatial/ } \\
\text { constructional }\end{array}$} & Case & $83.16 \pm 15.47$ & $82.09 \pm 14.56$ & $3.720(0.054)$ & $0.363(0.547)$ & $1.101(0.294)$ & \\
\hline & Control & $87.27 \pm 18.10$ & $87.79 \pm 15.48$ & & & & \\
\hline \multirow[t]{2}{*}{ Delayed memory } & Case & $83.89 \pm 13.94$ & $79.44 \pm 18.79$ & $51.580(<0.001)^{* *}$ & $0.021(0.884)$ & $3.311(0.069)$ & \\
\hline & Control & $91.31 \pm 12.74$ & $92.78 \pm 10.75$ & & & & \\
\hline rs2187473 & & $\mathrm{T} / \mathrm{T}+\mathrm{C} / \mathrm{T}$ & $\mathrm{CC}$ & & & & \\
\hline \multirow{2}{*}{$\begin{array}{l}\text { Immediate } \\
\text { memory }\end{array}$} & Case & $69.82 \pm 17.10$ & $75.87 \pm 18.13$ & $53.576(<0.001)^{* *}$ & $0.013(0.909)$ & $9.076(0.003)^{*}$ & $6.683(0.010)^{*}$ \\
\hline & Control & $88.25 \pm 13.45$ & $84.55 \pm 16.30$ & & & & $3.305(0.070)$ \\
\hline \multirow[t]{2}{*}{ Language } & Case & $81.00 \pm 18.46$ & $84.33 \pm 15.29$ & $29.004(<0.001)^{* * *}$ & $0.264(0.607)$ & $1.696(0.193)$ & \\
\hline & Control & $91.82 \pm 14.21$ & $91.41 \pm 14.19$ & & & & \\
\hline \multirow[t]{2}{*}{ Attention } & Case & $98.38 \pm 20.89$ & $102.67 \pm 16.10$ & $25.850(<0.001)^{* *}$ & $0.015(0.902)$ & $3.727(0.054)$ & \\
\hline & Control & $111.64 \pm 16.21$ & $109.26 \pm 15.83$ & & & & \\
\hline \multirow{2}{*}{$\begin{array}{l}\text { Visuospatial/ } \\
\text { constructional }\end{array}$} & Case & $81.21 \pm 15.88$ & $83.42 \pm 14.50$ & $5.310(0.022)^{*}$ & $0.017(0.895)$ & $2.236(0.135)$ & \\
\hline & Control & $88.47 \pm 15.34$ & $87.15 \pm 17.61$ & & & & \\
\hline \multirow[t]{2}{*}{ Delayed memory } & Case & $78.94 \pm 18.10$ & $83.22 \pm 15.67$ & $51.629(<0.001)^{* *}$ & $0.034(0.853)$ & $5.014(0.026)^{*}$ & $4.221(0.040)^{*}$ \\
\hline & Control & $94.07 \pm 9.22$ & $90.91 \pm 12.85$ & & & & $1.611(0.205)$ \\
\hline rs 2875623 & & $\mathrm{G} / \mathrm{G}+\mathrm{C} / \mathrm{G}$ & $\mathrm{CC}$ & & & & \\
\hline \multirow{2}{*}{$\begin{array}{l}\text { Immediate } \\
\text { memory }\end{array}$} & Case & $78.90 \pm 19.82$ & $73.36 \pm 17.56$ & $15.555(<0.001)^{* *}$ & $1.868(0.172)$ & $0.214(0.644)$ & \\
\hline & Control & $89.69 \pm 10.17$ & $85.58 \pm 15.90$ & & & & \\
\hline \multirow[t]{2}{*}{ Language } & Case & $83.62 \pm 18.49$ & $82.94 \pm 16.81$ & $5.426(0.020)^{*}$ & $0.193(0.660)$ & $0.302(0.583)$ & \\
\hline & Control & $90.00 \pm 9.36$ & $91.61 \pm 14.46$ & & & & \\
\hline \multirow[t]{2}{*}{ Attention } & Case & $113.75 \pm 12.39$ & $109.90 \pm 16.13$ & $6.526(0.011)^{* *}$ & $0.959(0.328)$ & $0.014(0.906)$ & \\
\hline & Control & $105.14 \pm 13.64$ & $101.17 \pm 17.96$ & & & & \\
\hline \multirow{2}{*}{$\begin{array}{l}\text { Visuospatial/ } \\
\text { constructional }\end{array}$} & Case & $84.10 \pm 17.31$ & $82.72 \pm 14.82$ & $3.3396(0.066)$ & $1.031(0.310)$ & $1.045(0.307)$ & \\
\hline & Control & $96.75 \pm 27.82$ & $87.04 \pm 15.84$ & & & & \\
\hline \multirow[t]{2}{*}{ Delayed memory } & Case & $86.72 \pm 11.39$ & $81.43 \pm 16.79$ & $6.526(0.011)^{* *}$ & $1.521(0.218)$ & $0.329(0.566)$ & \\
\hline & Control & $94.54 \pm 5.35$ & $91.83 \pm 12.06$ & & & & \\
\hline
\end{tabular}

Notes: ${ }^{*}$ p-value $<0.001$. ${ }^{*}$-value $<0.05$. 
Table 4 Genotype Polymorphisms' Distributions and Allele Frequencies of MIR34B/C in MDD Patients and Healthy Controls

\begin{tabular}{|c|c|c|c|c|c|c|c|c|c|c|c|c|}
\hline \multirow{2}{*}{$\frac{\text { SNPs }}{\text { rs4938723 }}$} & \multirow{2}{*}{ Type } & \multirow[t]{2}{*}{$\mathbf{n}$} & \multicolumn{3}{|c|}{ Genotyping (\%) } & \multirow[t]{2}{*}{$\chi^{2}$} & \multirow{2}{*}{ p-value } & \multicolumn{2}{|c|}{ Allele (\%) } & \multirow[t]{2}{*}{$\chi^{2}$} & \multirow[t]{2}{*}{ p-value } & \multirow[t]{2}{*}{ HWE-p } \\
\hline & & & $\mathrm{T} / \mathrm{T}$ & $\mathrm{T} / \mathrm{C}$ & $\mathrm{C} / \mathrm{C}$ & & & $\mathrm{T}$ & C & & & \\
\hline & Cases & 441 & $218(49.4)$ & $174(39.5)$ & $49(11.1)$ & 4.23 & 0.121 & $610(69.2)$ & $272(30.8)$ & 3.63 & 0.057 & 0.115 \\
\hline & Controls & 222 & $91(41.0)$ & $102(45.9)$ & $29(13.1)$ & & & $284(64.0)$ & $160(36.0)$ & & & 0.960 \\
\hline \multirow[t]{3}{*}{ rs2187473 } & & & $\mathrm{C} / \mathrm{C}$ & $\mathrm{C} / \mathrm{T}$ & $\mathrm{T} / \mathrm{T}$ & & & c & $\mathrm{T}$ & & & \\
\hline & Cases & 421 & $263(62.5)$ & $143(34.0)$ & $15(3.6)$ & 4.39 & 0.111 & $669(79.5)$ & $173(20.5)$ & 1.74 & 0.187 & 0.408 \\
\hline & Controls & 223 & $155(69.5)$ & $58(26.0)$ & $10(4.5)$ & & & $368(82.5)$ & $78(17.5)$ & & & 0.140 \\
\hline \multirow[t]{3}{*}{ rs28757623 } & & & $\mathrm{G} / \mathrm{G}$ & $\mathrm{G} / \mathrm{C}$ & $\mathrm{C} / \mathrm{C}$ & & & G & C & & & \\
\hline & Cases & 442 & $249(56.3)$ & $163(36.9)$ & $30(6.8)$ & 4.15 & 0.125 & $661(74.8)$ & $223(25.2)$ & 3.55 & 0.060 & 0.637 \\
\hline & Controls & 221 & $106(48.0)$ & $97(43.9)$ & $18(8.1)$ & & & $309(69.9)$ & $133(30.1)$ & & & 0.520 \\
\hline
\end{tabular}

performance in the delayed memory domain; this association was not present in healthy controls.

\section{The Link Between Depression and Cognition}

Our study demonstrated a detrimental relationship between MDD and cognitive functioning, which is consistent with results of previous studies. ${ }^{40,41,51,52} \mathrm{We}$ found differences in miR expression levels between MDD patients and healthy controls. We also found an association between higher peripheral blood leukocyte miR-34c-5p levels and deficits in working memory, delayed memory, and language in patients with MDD. Depressive disorders are usually associated with deficits in working, short-term, and long-term memory. ${ }^{53} \mathrm{In}$ this study, we found that cognitive functioning was significantly impaired in patients with MDD, which is consistent with results of previous clinical studies. ${ }^{10,11,56,57}$ However, our results indicated that there were no significant differences in the RBANS total score or the subscale scores for the attention, visuospatial/constructional, and language domains between the patients with MDD and healthy controls based on miR-34c.

\section{miR-34b/c and Depression}

miRs have been shown to be differentially expressed in neurons and could be key factors in the development and pathophysiology of depression. ${ }^{54,55}$ Furthermore, the expression levels of miR-34b and miR-34c were found to be abnormal in the prefrontal cortex in MDD patients and animal models of depression. ${ }^{28,55}$ In this study, we found associations between the rs2187473 CC genotype (located near MIR34B/C) and higher performance in the immediate memory and delayed memory domains in MDD patients but not in healthy controls. This indicates that rs2187473 polymorphism influences immediate memory and delayed memory performance under disease conditions where high levels of miR-34c levels are needed. These findings suggest that miR-34b/c may be predictive of cognitive dysfunction in patients with MDD.

\section{miR-34b/c and Cognition}

Impacts on language performance in patients with depression are still controversial. While some studies report dysfunction in language, ${ }^{58-60}$ others report no such deficits. ${ }^{61,62}$ Using a large cohort of the UK population, Cullen et al and Meijsen et al both observed an increase in language performance in MDD cases compared to controls. ${ }^{63,64}$ Because language deficits have only been reported in geriatric patients with depression $^{59}$ or in individuals with comorbid psychiatric disorders, ${ }^{65}$ it is possible that language deficits may be caused by certain forms of depression or the presence of other factors that impact cognition. Language performance is an intellectual measure of memories recalled by individuals, which may be influenced by population literacy. ${ }^{63} \mathrm{In}$ addition, the choice of subtests in the RBANS may have led to limitations in our ability to detect language deficits associated with mild to moderate depression, although Faust has reported that the RBANS test is sensitive to the neuropsychological deficits typically found in mild to moderate depression in adult patients with MDD.

It has become increasingly clear that hippocampal neurosynaptic and structural plasticity dysfunction may be involved in the etiology of cognitive deficits in MDD. ${ }^{21,22}$ miR-34c may play a regulatory role in the growth and 

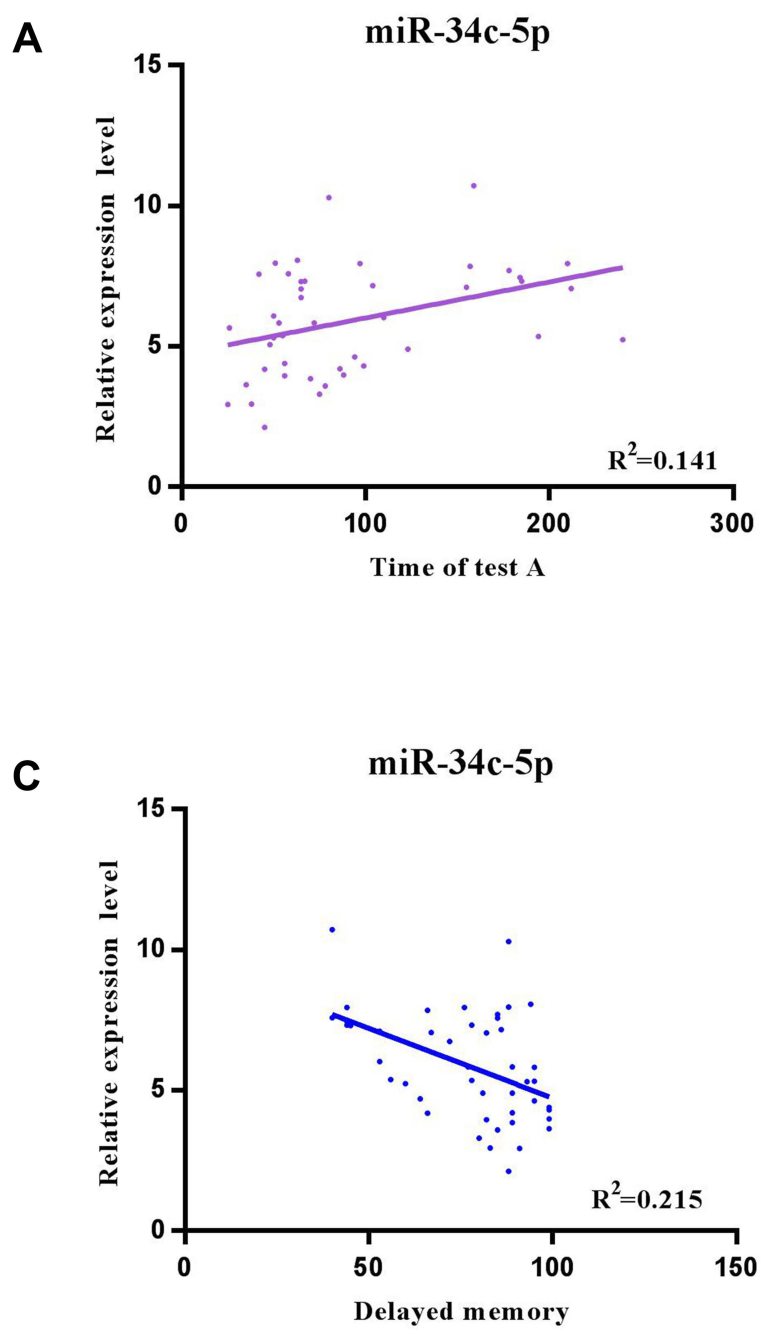

\section{B}

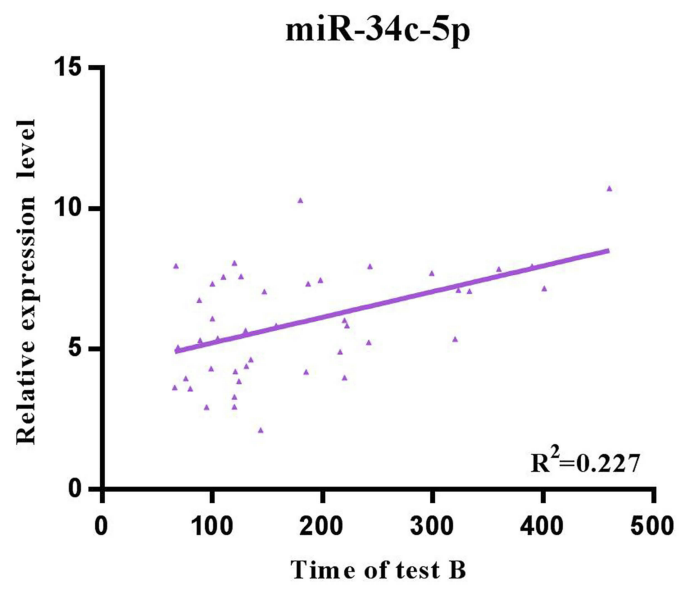

D

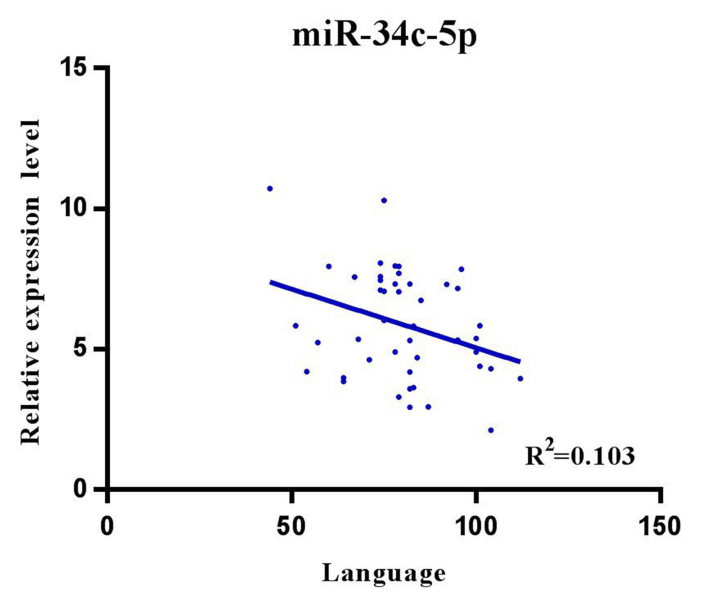

Figure 2 Pearson's correlation analyses of miR-34c expression levels and neuropsychological function. Significant negative correlations between miR-34c-5p expression level and both $(\mathbf{A})$ the language index score $(r=-0.320$, and $p=0.032)$ and $(\mathbf{B})$ the delayed memory index score $(r=-0.463, p=0.00 \mathrm{I})$ in patients with depression. Significant positive correlations between miR-34c-5p expression and the time required to complete both $(\mathbf{C})$ test $\mathrm{A}(r=0.375, \mathrm{P}=0.0 \mathrm{I})$ and $(\mathrm{D})$ test $\mathrm{B}(r=0.477$, $\mathrm{P}=0.00 \mathrm{I})$ of the TMT.

development of nerve cells. Kao et al reported that miR-34c overexpression in hippocampal neurons leads to shortened dendrites and decreased spine density, which are key structural components of memory formation and storage. ${ }^{66}$ Moreover, miR-34c is strongly involved in regulating the expression of genes related to the Notch signaling pathway, which play an important role in the regeneration of the central nervous system by regulating proliferation and differentiation. ${ }^{67,68}$ These fundamental biological evidences support our findings on the relationship between miR-34c and cognitive function.

\section{Study Limitations}

We note that our study has several limitations. Further experiments in larger samples are warranted, and it is also necessary to consider medication information. These studies would allow us to replicate our findings and to evaluate differential expression of miR-34c in subgroups of patients stratified based on cognitive function. Second, some studies have reported that cognitive deficits still exist when remitted. Other clinical information, including information on recurrent episodes and remission status, were not collected in the present study. These factors should be considered in statistical analysis, as they may influence cognitive function in patients with MDD.

In summary, we report our exploratory investigation of the influence of miRA-34c on cognitive dysfunction in a Chinese patient population with MDD. We found that higher levels of miR-34c correlated with deficits in working memory, delayed memory, and language in patients with MDD. Our findings suggest that miR-34c may be used as a predictor of cognitive dysfunction in patients with MDD. The polymorphism 
rs2187473 may be a potential genetic factor contributing to cognitive function in patients with MDD.

\section{Acknowledgments}

This study was supported by the National Natural Science Youth Fund Project (81601192, 81701345), the National Key Research and Development Program of China (2016YFC1307103), the National Clinical Research Center on Mental Disorders (2015BAI13B02), the National Key Basic Research Program (No. 2013CB531305), the Program for the Outstanding Innovative Teams of Higher Learning Institutions of Shanxi, and the Doctoral Fund of Shanxi Medical University (BS03201635).

\section{Disclosure}

The authors declare that they have no competing interests.

\section{References}

1. Smith K, De Torres IBC. Mental health: a world of depression. Nature. 2014;515(7526):180-181. doi:10.1038/515180a

2. Huang Y, Wang Y, Wang H, et al. Prevalence of mental disorders in China: a cross-sectional epidemiological study. Lancet Psychiatry. 2019;6(3):211-224. doi:10.1016/S2215-0366(18)30511-X

3. Belmaker RH, Agam G. Major depressive disorder. $N$ Engl $J$ Med. 2008;358(17):1869. doi:10.1056/NEJMra073096

4. Bromet E, Andrade LH, Hwang I, et al. Cross-national epidemiology of DSM-IV major depressive episode. BMC Med. 2011;9(1):90. doi:10.1186/1741-7015-9-90

5. Hartog HMD, Derix MMA, Bemmel ALV, Kremer B, Jolles J. Cognitive functioning in young and middle-aged unmedicated out-patients with major depression: testing the effort and cognitive speed hypotheses. Psychol Med. 2003;33(8):1443-1451. doi:10.1017/ S003329170300833X

6. Porter RJ, Bourke C, Gallagher P. Neuropsychological impairment in major depression: its nature, origin and clinical significance. Aust NZJ Psychiatry. 2007;41(2):115-128. doi:10.1080/00048670601109881

7. Hammar A, Ardal G. Cognitive functioning in major depression-a summary. Front Hum Neurosci. 2009;3:26. doi:10.3389/ neuro.09.026.2009

8. Harvey PO, Le Bastard G, Pochon JB, et al. Executive functions and updating of the contents of working memory in unipolar depression. $J$ Psychiatr Res. 2004;38(6):567-576. doi:10.1016/j.jpsychires. 2004.03.003

9. Rogers MA, Kasai K, Koji M, et al. Executive and prefrontal dysfunction in unipolar depression: a review of neuropsychological and imaging evidence. Neurosci Res (N Y). 2004;50(1):1-11. doi:10.1016/j.neures.2004.05.003

10. Lee Rico SC, Hermens Daniel F, Porter Melanie A, RedobladoHodge MA. A meta-analysis of cognitive deficits in first-episode major depressive disorder. J Affect Disord. 2012;140(2):113-124. doi:10.1016/j.jad.2011.10.023

11. McDermott Lisa M, Ebmeier Klaus P. A meta-analysis of depression severity and cognitive function. $J$ Affect Disord. 2009;119(1-3):1-8. doi:10.1016/j.jad.2009.04.022

12. Faust K, Nelson Brady D, Sarapas C, Pliskin Neil H. Depression and performance on the repeatable battery for the assessment of neuropsychological status. Appl Neuropsychol Adult. 2017;24(4):350-356. doi:10.1080/23279095.2016.1185426
13. Jaeger J, Berns S, Uzelac S, Davis-Conway S. Neurocognitive deficits and disability in major depressive disorder. Psychiatry Res. 2006;145(1):39-48. doi:10.1016/j.psychres.2005.11.011

14. Hasselbalch Bo J, Ulla K, Vedel KL. Cognitive impairment in the remitted state of unipolar depressive disorder: a systematic review. J Affect Disord. 2011;134(1-3):20-31. doi:10.1016/j.jad.2010.11.011

15. Schultz Susan K, Ellingrod Vicki L, Moser David J, et al. The influence of cognitive impairment and psychiatric symptoms on daily functioning in nursing facilities: a longitudinal study. Ann Clin Psychiatry. 2002;14(4):209-213. doi:10.3109/10401230 209147459

16. Hinton LS, Farias T, Wegelin J. Neuropsychiatric symptoms are associated with disability in cognitively impaired Latino elderly with and without dementia: results from the sacramento area latino study on aging. Int $J$ Geriatr Psychiatry. 2008;23(1):102-108. doi:10.1002/gps.1952

17. Lavretsky H, Zheng L, Weiner MW, Mungas D, Reed B, Kramer JH. Association of depressed mood and mortality in older adults with and without cognitive impairment in a prospective naturalistic study. $\mathrm{Am}$ $J$ Psychiatry. 2010;167(5):589-597. doi:10.1176/appi.ajp.2009.09 020280

18. Okura T, Plassman Brenda L, Steffens David C, Llewellyn David J, Potter Guy G, Langa Kenneth M. Prevalence of neuropsychiatric symptoms and their association with functional limitations in older adults in the United States: the aging, demographics, and memory study. J Am Geriatr Soc. 2009;58(2):330-337. doi:10.1111/j.15325415.2009.02680.x

19. Guo J, Liu Z, Dai H, et al. Preliminary investigation of the influence of CREB1 gene polymorphisms on cognitive dysfunction in Chinese patients with major depression. Int J Neurosci. 2014;124(1):22-29. doi:10.3109/00207454.2013.816956

20. Hui L, Han M, Du XD, et al. Serum ApoB levels in depressive patients: associated with cognitive deficits. Sci Rep. 2017;7 (1):39992. doi:10.1038/srep39992

21. Duric V, Banasr M, Stockmeier Craig A, et al. Altered expression of synapse and glutamate related genes in post-mortem hippocampus of depressed subjects. Int J Neuropsychopharmacol. 2013;16(1):69-82. doi:10.1017/S1461145712000016

22. Malki K, Pain O, Tosto MG, Du Rietz E, Carboni L, Schalkwyk LC. Identification of genes and gene pathways associated with major depressive disorder by integrative brain analysis of rat and human prefrontal cortex transcriptomes. Transl Psychiatry. 2015;5(3):e519. doi: $10.1038 /$ tp. 2015.15

23. Schratt Gerhard M, Tuebing F, Nigh Elizabeth A, et al. A brain-specific microRNA regulates dendritic spine development. Nature. 2006;439(7074):283-289. doi:10.1038/nature04367

24. Nadim WD, Simion V, Benedetti H, Pichon C, Baril P, MorissetLopez S. MicroRNAs in neurocognitive dysfunctions: new molecular targets for pharmacological treatments? Curr Neuropharmacol. 2017;15(2):260-275. doi:10.2174/1570159X14666160709001441

25. Baudry A, Mouillet-Richard S, Schneider B, Jean-Marie. L, Odile K. miR-16 targets the serotonin transporter: a new facet for adaptive responses to antidepressants. Science. 2010;329(5998):1537-1541. doi:10.1126/science.1193692

26. Hansen Katelin F, Karl O. MicroRNA as therapeutic targets for treatment of depression. Neuropsychiatr Dis Treat. 2013;9:1011-1021. doi:10.2147/NDT.S34811

27. Lopez JP, Lim R, Cruceanu C, et al. miR-1202 is a primate-specific and brain-enriched microRNA involved in major depression and antidepressant treatment. Nat Med. 2014;20(7):764-768. doi: $10.1038 / \mathrm{nm} .3582$

28. Smalheiser Neil R, Lugli G, Rizavi HS, et al. MicroRNA expression is down-regulated and reorganized in prefrontal cortex of depressed suicide subjects. PLoS One. 2012;7(3):e33201. doi:10.1371/journal. pone. 0033201 
29. Smalheiser Neil R, Lugli G, Zhang H, et al. Expression of microRNAs and other small RNAs in prefrontal cortex in schizophrenia, bipolar disorder and depressed subjects. PLoS One. 2014;9 (1):e86469. doi:10.1371/journal.pone.0086469

30. Belzeaux R, Bergon A, Jeanjean V, et al. Responder and nonresponder patients exhibit different peripheral transcriptional signatures during major depressive episode. Transl Psychiatry. 2012;2(11): e185. doi:10.1038/tp.2012.112

31. Liu X, Zhang L, Cheng $\mathrm{K}$, et al. Identification of suitable plasma-based reference genes for miRNAome analysis of major depressive disorder. $J$ Affect Disord. 2014;163:133-139. doi:10.1016/j.jad.2013.12.035

32. Oved K, Morag A, Pasmanik-Chor M, et al. Genome-wide miRNA expression profiling of human lymphoblastoid cell lines identifies tentative SSRI antidepressant response biomarkers. Pharmacogenomics. 2012;13(10):1129-1139. doi:10.2217/pgs.12.93

33. Haramati S, Navon I, Issler O, et al. MicroRNA as repressors of stress-induced anxiety: the case of amygdalar miR-34. J Neurosci. 2011;31(40):14191-14203. doi:10.1523/JNEUROSCI.1673-11.2011

34. Bocchio-Chiavetto L, Maffioletti E, Bettinsoli P, et al. Blood microRNA changes in depressed patients during antidepressant treatment. Eur Neuropsychopharmacol. 2013;23(7):602-611. doi:10.1016/j.euroneuro.2012.06.013

35. Zovoilis A, Agbemenyah HY, Agis-Balboa RC, et al. microRNA-34c is a novel target to treat dementias. EMBO J. 2011;30 (20):4299-4308. doi:10.1038/emboj.2011.327

36. Ning S, Lei L, Wang Y, et al. Preliminary comparison of plasma notch-associated microRNA-34b and $-34 \mathrm{c}$ levels in drug naive, first episode depressed patients and healthy controls. J Affect Disord. 2016;194:109-114. doi:10.1016/j.jad.2016.01.017

37. Xu C, Yang C, Zhang A, Xu Y, Li X, Liu Z. The interaction of mir-34b/c polymorphisms and negative life events increases susceptibility to major depressive disorder in han chinese population. Neurosci Lett. 2017;651:65-71. doi:10.1016/j.neulet.2017.04.061

38. Yiqing H, Liu X, Liao Y, et al. Role of miR-34c in the cognitive function of epileptic rats induced by pentylenetetrazol. Mol Med Rep. 2018;17(3):4173-4180. doi:10.3892/mmr.2018.8441

39. Shu-e C, Tian J, Chen S, et al. Role of miR-34c in ketamine-induced neurotoxicity in neonatal mice hippocampus. Cell Biol Int. 2015;39 (2):164-168. doi:10.1002/cbin.10349

40. Li M, Lu S, Wang G, Feng L, Fu B, Zhong N. Emotion, working memory, and cognitive control in patients with first-onset and previously untreated minor depressive disorders. J Int Med Res. 2016;4 (3):529-541. doi:10.1177/0300060516639169

41. Li M, Zhong N, Lu S, et al. Cognitive behavioral performance of untreated depressed patients with mild depressive symptoms. PLoS One. 2016;11(1):e0146356. doi:10.1371/journal.pone.0146356

42. Baune BT, Miller R, Mcafoose J, Johnson M, Quirk F, Mitchell D. The role of cognitive impairment in general functioning in major depression. Psychiatry Res. 2010;176(2-3):0-189. doi:10.1016/j. psychres.2008.12.001

43. Randolph C, Tierney MC, Mohr E, Chase TN. The repeatable battery for the assessment of neuropsychological status (RBANS): preliminary clinical validity. J Clin Exp Neuropsychol. 1998;20(3):310-319. doi:10.1076/jcen.20.3.310.823

44. Sánchez-Cubillo I, Periáñez JA, Adrover-Roig D, et al. Construct validity of the trail making test: role of task-switching, working memory, inhibition/interference control, and visuomotor abilities. J Int Neuropsychol Soc. 2009;15(3):438-450. doi:10.1017/S1355617709090626

45. Gold JM, Queern C, Iannone VN, Buchanan RW. Repeatable battery for the assessment of neuropsychological status as a screening test in schizophrenia I: sensitivity, reliability, and validity. Am J Psychiatry. 1999;156(12):1944-1950. doi:10.1176/ajp.156.12.1944

46. Zhong N, Jiang $\mathrm{H}$, Wu J, et al. Reliability and validity of the CogState battery Chinese language version in schizophrenia. PLoS One. 2013;8(9):e74258. doi:10.1371/journal.pone.0074258
47. Ning S, Xu Y, Wang Y, et al. The combined effect of norepinephrine transporter gene and negative life events in major depression of Chinese Han population. J Neural Transm. 2008;115 (12):1681-1686. doi:10.1007/s00702-008-0109-5

48. Buetow KH, Edmonson M, MacDonald R, et al. High-throughput development and characterization of a genomewide collection of gene-based single nucleotide polymorphism markers by chip-based matrix-assisted laser desorption/ionization time-of-flight mass spectrometry. Proc Natl Acad Sci U S A. 2001;98(2):581-584. doi:10.1073/pnas.98.2.581

49. Sun T, Gao Y, Tan W, et al. A six-nucleotide insertion-deletion polymorphism in the CASP8 promoter is associated with susceptibility to multiple cancers. Nat Genet. 2007;39(5):605-613. doi:10.1038/ng2030

50. Dupont WD, Plummer WD. Power and sample size calculations for studies involving linear regression. Control Clin Trials. 1998;19 (6):589-601. doi:10.1016/S0197-2456(98)00037-3

51. Ravnkilde B, Videbech P, Clemmensen K, Egander A, Rasmussen NA, Rosenberg R. Cognitive deficits in major depression. Scand J Psychol. 2002;43(3):239-251. doi:10.1111/ 1467-9450.00292

52. Pakarinen M, Vanhanen S, Sinikallio S. Depressive burden is associated with a poorer surgical outcome among lumbar spinal stenosis patients: a 5-year follow-up study. Spine J. 2014;14(10):2392-2396. doi:10.1016/j.spinee.2014.01.047

53. Williams RA, Hagerty BM, Cimprich B, Therrien B, Bay E, Oe H. Changes in directed attention and short-term memory in depression. J Psychiatr Res. 2000;34(3):227-238. doi:10.1016/S0022-3956(00) 00012-1

54. Dwivedi Y. Evidence demonstrating role of microRNAs in the etiopathology of major depression. $J$ Chem Neuroanat. 2011;42 (2):142-156. doi:10.1016/j.jchemneu.2011.04.002

55. Aschrafi A, Verheijen Jan M, Gordebeke Peter M, et al. MicroRNA326 acts as a molecular switch in the regulation of midbrain urocortin 1 expression. J Psychiatry Neurosci. 2016;41(5):342-353. doi:10.1503/jpn.150154

56. Rock PL, Roiser JP, Riedel WJ, Blackwell AD. Cognitive impairment in depression: a systematic review and meta-analysis. Psychol Med. 2014;44(10):2029-2040. doi:10.1017/S0033291713002535

57. Zaninotto L, Solmi M, Veronese N. A meta-analysis of cognitive performance in melancholic versus non-melancholic unipolar depression. J Affect Disord. 2016;201:15-24. doi:10.1016/j. jad.2016.04.039

58. Neu P, Bajbouj M, Schilling A, Godemann F, Berman RM, Schlattmann P. Cognitive function over the treatment course of depression in middle-aged patients: correlation with brain MRI signal hyperintensities. J Psychiatr Res. 2005;39(2):129-135. doi:10.1016/j. jpsychires.2004.06.004

59. O'Bryant SE, Hall JR, Cukrowicz KC, et al. The differential impact of depressive symptom clusters on cognition in a rural multi-ethnic cohort: a Project FRONTIER study. Int J Geriatr Psychiatry. 2011;26 (2):199-205. doi:10.1002/gps.2514

60. Sexton CE, McDermott L, Kalu UG, et al. Exploring the pattern and neural correlates of neuropsychological impairment in late-life depression. Psychol Med. 2012;42(6):1195-1202. doi:10.1017/ S0033291711002352

61. Andersson S, Hui L, Han M, Du XD. Neuropsychological function in unmedicated recurrent brief depression. J Affect Disord. 2010;125 (1-3):155-164. doi:10.1016/j.jad.2009.12.023

62. Nelson Brady D. Frontal brain asymmetry in depression with comorbid anxiety: a neuropsychological investigation. J Abnorm Psychol. 2012;121(3):579-591. doi:10.1037/a0027587

63. Meijsen JJ, Campbell A, Hayward C, Porteous DJ, Deary IJ, Marioni RE. Phenotypic and genetic analysis of cognitive performance in major depressive disorder in the generation scotland: scottish family health study. Transl Psychiatry. 2018;8(1):63. doi:10.1038/s41398-018-0111-0 
64. Cullena B, Nichollb BI, Mackayc DF, Martina D, Smith DJ. Cognitive function and lifetime features of depression and bipolar disorder in a large population sample: cross-sectional study of 143,828 uk biobank participants. Eur Psychiatry. 2015;30 (8):950-958. doi:10.1016/j.eurpsy.2015.08.006

65. Baune Bernhard T, Oved K, Morag A, Pasmanik-Chor M. Impact of psychiatric and medical comorbidity on cognitive function in depression. Psychiatry Clin Neurosci. 2009;63(3):392-400. doi:10.1111/j.14401819.2009.01971.x

66. Kao YC, Wang I, Tsai KJ. miRNA-34c overexpression causes dendritic loss and memory decline. Int J Mol Sci. 2018;19(8):2323. doi:10.3390/ijms 19082323
67. Guo YJ, Zhang ZJ, Wang SH, et al. Notch1 signaling, hippocampal neurogenesis and behavioral responses to chronic unpredicted mild stress in adult ischemic rats. Prog Neuropsychopharmacol Biol Psychiatry. 2009;33(4):688-694. doi:10.1016/j.pnpbp.2009.03.022

68. Wang S, Yuan Y, Xia W, et al. Neuronal apoptosis and synaptic density in the dentate gyrus of ischemic rats' response to chronic mild stress and the effects of Notch signaling. PLoS One. 2012;7(8): e42828. doi:10.1371/journal.pone.0042828

\section{Publish your work in this journal}

Neuropsychiatric Disease and Treatment is an international, peerreviewed journal of clinical therapeutics and pharmacology focusing on concise rapid reporting of clinical or pre-clinical studies on a range of neuropsychiatric and neurological disorders. This journal is indexed on PubMed Central, the 'PsycINFO' database and CAS, and is the official journal of The International Neuropsychiatric Association (INA). The manuscript management system is completely online and includes a very quick and fair peer-review system, which is all easy to use. Visit http://www.dovepress.com/testimonials.php to read real quotes from published authors. 